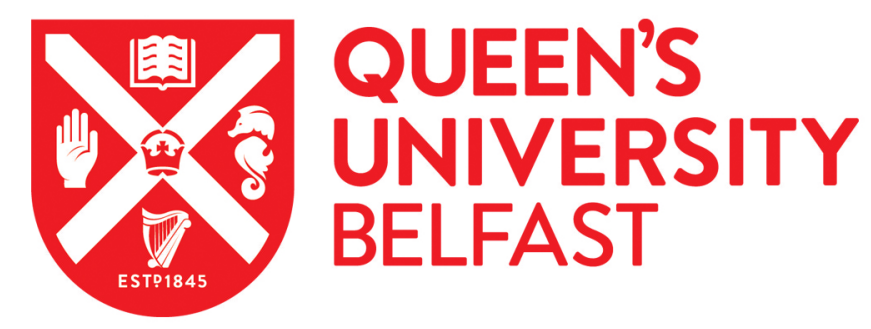

\title{
Highly sensitive electrochemical detection of the marine toxins okadaic acid and domoic acid with carbon black modified screen printed electrodes
}

Neils, J. L. D., Migliorelli , D., Muhlebach, L., Generelli, S., Stewart, L., Elliott, C. T., \& Campbell, K. (2021).

Highly sensitive electrochemical detection of the marine toxins okadaic acid and domoic acid with carbon black modified screen printed electrodes. Talanta, 228, [122215]. https://doi.org/10.1016/j.talanta.2021.122215

Published in:

Talanta

Document Version:

Peer reviewed version

Queen's University Belfast - Research Portal:

Link to publication record in Queen's University Belfast Research Portal

\section{Publisher rights}

Copyright 2021 Elsevier.

This manuscript is distributed under a Creative Commons Attribution-NonCommercial-NoDerivs License

(https://creativecommons.org/licenses/by-nc-nd/4.0/), which permits distribution and reproduction for non-commercial purposes, provided the author and source are cited.

\section{General rights}

Copyright for the publications made accessible via the Queen's University Belfast Research Portal is retained by the author(s) and / or other copyright owners and it is a condition of accessing these publications that users recognise and abide by the legal requirements associated with these rights.

Take down policy

The Research Portal is Queen's institutional repository that provides access to Queen's research output. Every effort has been made to ensure that content in the Research Portal does not infringe any person's rights, or applicable UK laws. If you discover content in the Research Portal that you believe breaches copyright or violates any law, please contact openaccess@qub.ac.uk. 
Highly sensitive electrochemical detection of the marine toxins okadaic acid and domoic acid with carbon black modified screen printed electrodes

Formatted: No Spacing, Left, Line spacing: single

Joost L.D. Nelis ${ }^{1 *}$, Davide Migliorelli ${ }^{2}$, Lea Mühlebach ${ }^{2}$, Silvia Generelli ${ }^{2}$, Linda Stewart ${ }^{1}$, Christopher T. Elliott ${ }^{1}$ and Katrina Campbell ${ }^{1}$

1. Institute for Global Food Security, Queen's University, Belfast, 19 Chlorine Gardens, Belfast, UK, BT9 $5 \mathrm{DL}$.

2. CSEM SA, Bahnhofstrasse 1, 7302, Landquart, Switzerland.

*Corresponding Author: J.L.D Nelis, Email: J.Nelis@qub.ac.uk 
Abstract: A novel electrochemical immunosensor for the detection of the important marine biotoxins domoic acid (DA) and okadaic acid (OA) was developed. The sensors used carbon black modified screen-printed electrodes (CB-SPE) obtained using a high-throughput method. The electrochemical performance and stability of CB modified SPEs and bare carbon SPEs (c-SPEs) were compared using cyclic voltammetry and electrochemical impedance spectroscopy. CB-SPEs showed improved longterm (at least six months) stability and electro-catalytic properties compared with c-SPEs. The CB-SPEs were bio-functionalized with DA or OA protein-conjugates and used to develop two indirect competitive immunosensors using differential pulse voltammetry (DPV). The DPV signals obtained for the $O A$ and DA immunosensors fitted well to four-parameter dose-response curves $\left(R^{2}>0.98\right)$ and showed excellent LODs (LOD=1.7 $\mathrm{ng} \mathrm{mL}^{-1}$ for DA in buffer; LOD=1.9 $\mathrm{ng} \mathrm{mL}^{-1}$ for DA in mussel extract; $L O D=0.15 \mathrm{ng} \mathrm{mL}^{-1}$ for $O A$ in buffer; $L O D=0.18 \mathrm{ng} \mathrm{mL}^{-1}$ for $O A$ in mussel extract). No significant interference of the naturally co-occurring marine toxins saxitoxin, tetrodotoxin and OA was detected for the DA immunosensor. Similarly, for the OA immunosensor saxitoxin, tetrodotoxin and DA did not cross-react and very limited interference was observed for the dinophysis toxins DTX-1, DTX-2 and DTX-3 (OA congeners). Moreover, both immunosensors remained stable after at least 25 days of storage at $4{ }^{\circ} \mathrm{C}$. This work demonstrates the potential of affordable, mass-produced nanomaterialmodified SPEs for marine toxin detection in shellfish.

Keywords: Carbon Black; Toxin; Electrochemistry; Pulsed Voltammetry; Immunoassay; Immunosensor; Screen Printed Electrode 


\section{Introduction}

Global food security is under immense pressure due to population growth, declining fresh water supplies, climate change and the struggle to increase crop production without further biodiversity depletion[1,2]. An interesting possibility is to increase sustainable aquaculture production in developing countries, especially the culturing of lower trophic and extractive species, such as molluscs, since such species can feed on waste products and reduce the water nutrient load [3]. Moreover, aquaculture is profitable and the sector has a projected growth of $>50 \%$ in Africa over the next decade [3]. Although these figures are encouraging, it means that shellfish farming will increase in remote areas with limited analytical facilities to test for a range of key regulated and frequently occurring marine toxins, such as okadaic acid (OA) and domoic acid (DA). These toxins, which do not degrade through cooking or freezing, accumulate within filter feeders and can cause gastrointestinal illness (OA and analogues) and in some cases neurological damage (DA), [4], [5]. Unfortunately, the occurrence of the harmful algal blooms producing these toxins is increasing globally as a result of eutrophication [6] and climate change [7]. Furthermore, marine toxin containing algae can cause reduced feeding in mussels and affect mussel quality [8]. Thus, developing practical solutions enabling point-of-site monitoring by the non-expert is paramount to answer to the global need for such tools and ensure that sustainable aquaculture production of shellfish is achieved safely and in an affordable manner.

Electrochemical biosensors are a potential option for this purpose [9]. Especially because they can often provide more sensitive and quantitative results than their colorimetric equivalents (e.g. the lateral flow assay) [10]. Quantification of toxin will allow important decision making regarding shellfish harvesting and limiting food waste. Moreover, affordable and disposable sensors can be made using techniques such as screen-printing or inkjet while, unlike in colorimetric assays, matrix issues such as turbidity and colour do not affect the measurements. As a result electrochemical methods may be better suited for analyses in complex food matrices [11] [12]. 
Sensitive DA detection with carbon screen-printed electrodes (c-SPEs) has been reported by Micheli et al., [13] with a limit of detection (LOD) of $5 \mathrm{ng} \mathrm{mL}^{-1}$ and Kania et al., [14] with a LOD of $0.1 \mathrm{ng} \mathrm{mL}^{-1}$. However, both LODs were calculated in buffer and c-SPEs have been known to suffer from fouling issues. Moreover, sensitivity of carbon electrodes can be limited. For instance, the maximum and minimum currents recorded by Micheli et al., [13] only varied between $\sim 1-10 \mu \mathrm{A}$. In another study

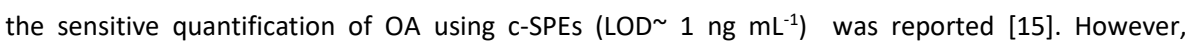
approximately $1.5 \mu \mathrm{g}$ of unconjugated OA was covalently immobilised to the bare working electrode directly, without the use of a protein-based bioconjugate, making the sensor very expensive due to the high cost of the toxin. In a separate study using chronoamperometric detection of tetrodotoxin with modified screen-printed gold electrodes, it was observed that direct functionalisation of the electrode surface with tetrodotoxin required a 40-fold increased use of the toxin in comparison with a colorimetric method [9]. Reduction in toxin use may be achieved by: (i) using a suitable nanomaterial to modify the surface of the working electrode (WE) to limit fouling which helps to limit capacitive current; (ii) combining this with pulsed voltammetry to increase the faradaic/capacitive current ratio; and (iii) using toxin-protein conjugates to limit the required toxin amount [16-19]. Improved sensitivity may also facilitate analyses with portable instruments with lower resolution (such as the Sensit Smart (https://www.palmsens.com/product/sensit-smart/).

Modifying SPEs with nanomaterials can substantially increase SPE sensitivity as shown for the quantification of OA (LOD 8 pM in buffer) with Au-nanoparticle and phosphorene modified SPEs by differential pulse voltammetry (DPV) [20], and other SPE based assays [21,22]. Moreover, such modifications were shown to improve toxin detection with various electrochemical biosensors due to an increase in electroactive surface area and better electron transfer [23]. However, it has been noted, in a review by the Palleschi group, that the use of these materials is often expensive and not suited for mass-production of the sensors due to difficulties in implementing the complex surface modification protocols required [12]. One very interesting nanomaterial that may overcome these issues for carbon SPE modification, is a by-product created by partial combustion of aromatic 
hydrocarbons in oil furnaces. This material, carbon black (CB), is particularly advantageous for C-SPE modification since it has been shown to match or outperform carbon nanotubes, graphene oxide and reduced graphene oxide-modified SPEs in terms of background currents and electrocatalytic activity. Moreover, the material is low cost $\left(\sim 1 € \mathrm{Kg}^{-1}\right)$, improves sensitivity, is resistant to fouling, has stable dispersions ( 2 weeks), and no pre-treatments are required $[17,24-26]$. The potential of various types of $\mathrm{CB}$ for electrochemical sensing have recently been compared [27]. Of the CB types compared, N220 has great potential for C-SPE modification although some other good alternative CB types also exist (especially N115 and HP 160). The main features that makes these CBs performant for electrochemical sensors are, (i) their small size $(10-40 \mathrm{~nm})$, which ensures compact and uniform film formation, (ii) the high number of defect sites in the carbon onions due to incomplete graphitization, and, (iii) the high $\mathrm{C}-\mathrm{O}$ content, especially $-\mathrm{O}-\mathrm{C}=\mathrm{O}$ content. These last two features play a crucial role in the electro-catalytic performance of the electrode [27]. Indeed, N220 has been successfully used for the detection of a variety of compounds [24] [18]. However, the reported devices have mainly been made through manual modification of the WE using multiple drop-casting steps and have rarely been used for the development of immunosensors. In order to better adapt the technology for large-scale sensor production, a faster and automated c-SPE modification procedure is needed. Additionally, detailed stability studies of such SPEs are required to determine storage possibilities and enable commercial application of the technology. Finally, a biosensing approach that is easily made compatible for immunosensors targeting various targets may enhance piggybacking potential without lengthy assay development. Such versatility may enable rapid application of the technology for the detection of a multitude of targets.

In the present study, an automated modification-strategy suitable for mass-production of N220 modified SPES (CB-SPEs) using a one-drop casting step is described. The performance and six-month storage stability of the developed CB-SPEs were characterised in detail and compared with the stability of c-SPEs. Finally, the sensors were used to develop two separate biosensors, following the same immunoassay format, for the detection of DA and OA in mussels. 


\section{Material and methods}

\section{Chemicals, equipment and software}

A detailed description of the chemicals, equipment and software can be found in the supplementary information. Monoclonal anti-DA and anti-OA mouse antibodies (DA-mAb and OA-mAb) were developed within the Institute for Global Food Security and previously characterized [28,29].

\section{Bioconjugate preparation}

For OA conjugation to ovalbumin (OVA) the study of Llamas et al., [30] was followed. Briefly, Nhydroxysulfosuccinimide $(20 \mu \mathrm{mol})$ and 1-Ethyl-3-(3-dimethylaminopropyl)carbodiimide $(40 \mu \mathrm{mol})$ were dissolved separately in 2-(N-Morpholino)ethanesulfonic acid (MES) buffer (50 mM, $500 \mathrm{mM}$ $\mathrm{NaCl}, \mathrm{pH} 5.0,50 \mu \mathrm{l})$ and added to a solution containing $\mathrm{OA}(2.4 \mu \mathrm{mol})$ in anhydrous dimethylformamide (DMF) $(100 \mu l)$. The mixture was incubated for 30 minutes at room temperature (RT) to activate the OA. OVA (5.0 mg) was dissolved in phosphate-buffered saline (PBS) (800 $\mu \mathrm{l}, \mathrm{pH} 7.2)$, and pyridine (10 $\mu l)$ added to minimise precipitation. The activated OA mixture was added dropwise to the solution to ensure homogeneous hapten conjugation. The mixture was incubated for $12 \mathrm{~h}$ at $25^{\circ} \mathrm{C}$ and purified by dialysis against $\mathrm{NaCl}(0.5 \mathrm{mM})$. For DA conjugation to bovine serum albumin (BSA) a previously characterised conjugate [18] was used using a previously described protocol [31]. Briefly, 8 and 16 $\mu \mathrm{mol}$ of $\mathrm{N}$-hydroxysuccinimide and dicyclohexylcarbodiimide were individually dissolved in DMF (50 $\mu \mathrm{L})$ and added to DA (3.2 $\mu \mathrm{mol}$; dissolved in $100 \mu \mathrm{L}$ of DMF). The solution was mixed and left to react by slowly stirring for $4 \mathrm{hr}$ at RT then centrifuged (1000 RCF, $10 \mathrm{~min}, 20^{\circ} \mathrm{C}$ ). The supernatant was added drop wise to a solution of $0.9 \mathrm{~mL}$ of borax buffer (made using boric acid; $\mathrm{pH}$ 8.7) containing $5 \mathrm{mg}$ of BSA while stirring. This mixture was left to react for $4 \mathrm{hr}$, dialyzed using $10 \mathrm{kDa}$ molecular weight cut off cartridges against $0.5 \mathrm{mM}$ PBS $(4 \times 5 \mathrm{~L} ; 6 \mathrm{~h})$ and ultrapure water $(1 \times 5 \mathrm{~L} ; 6 \mathrm{~h})$, and finally stored frozen at $-40^{\circ} \mathrm{C}$. 


\section{SPE manufacturing and modification}

The reference electrode was printed with silver/silver chloride ink. The counter electrode and WE (geometric area of $0.0314 \mathrm{~cm}^{2}$ ) were printed with graphite ink. Polymeric dielectric ink was used to insulate the electrodes. Electrodes were cured in an oven in between each printing step. For SPE modification with $\mathrm{CB}, 3 \mathrm{mg} \mathrm{mL}^{-1} \mathrm{CB}$ dispersions were made in DMF: $\mathrm{H}_{2} \mathrm{O}(1: 1, \mathrm{v} / \mathrm{v})$ by sonification using a Hielscher's UP 200ST. Various amounts of the dispersions were dropcasted on the WE using a Biodot XYZ3210 dispenser. Optimum drop deposition was evaluated visually (Fig. S1) in terms of WE coverage and determined to be $1.0 \mu \mathrm{L}$. The dropcasted SPEs were dried in a humidity chamber (65\% humidity; $25-23^{\circ} \mathrm{C}$; overnight) to ensure a uniform coverage of the WE and avoid coffee-ring formation.

\section{Electrochemical characterization}

Cyclic voltammetry (CV) experiments were performed in $0.1 \mathrm{M} \mathrm{KCl}$ in the absence or presence of 5 $\mathrm{mM}\left[\mathrm{Fe}(\mathrm{CN})_{6}\right]^{3-/ 4-}$. Potential was scanned from -0.3 to $0.6 \mathrm{~V}$ with a scan rate of $0.05 \mathrm{~V} \mathrm{~s}$ and a step potential of $0.01 \mathrm{~V}$ for 2 cycles, except for the $\mathrm{CV}$ experiments used to determine the active surface area where scan rates were varied (between 0.01 and $0.5 \mathrm{~V} \mathrm{~s}^{-1}$ ). Electrochemical impedance spectroscopy (EIS) experiments were conducted in $1 \mathrm{mM}\left[\mathrm{Fe}(\mathrm{CN})_{6}\right]^{3-/ 4-}$ with $0.1 \mathrm{M} \mathrm{KCl}$. The applied potential was $0 \mathrm{~V}$ versus the open circuit potential $\left(\mathrm{V}_{\mathrm{OCP}}\right)$ and the frequency range was varied from 100 $\mathrm{kHz}$ to $0.1 \mathrm{~Hz}$ using a $10 \mathrm{mV}$ amplitude. DPV was performed over a potential range from -200 to 500 $\mathrm{mV}$ at a scan rate of $300 \mathrm{mV} \mathrm{s}^{-1}$ and a potential step of $30 \mathrm{mV}$. The pulse amplitude was set at $70 \mathrm{mV}$ and pulse width at $0.1 \mathrm{~s}$. DPV measurements were used for the electrochemical immunoassay (see below) and to determine the sensitivity of bare and CB-modified SPEs for 1-naphthol. For the latter, 1-naphthol concentration was varied from $0.010 \mathrm{mM}$ to $5 \mathrm{mM}$.

\section{Electrochemical immunoassays}

Various concentrations $\left(7.5 \mu \mathrm{g} \mathrm{mL}^{-1}\right.$ to $\left.30 \mu \mathrm{g} \mathrm{mL}^{-1}\right)$ of BSA-DA, OVA-OA and BSA solution in carbonate buffer (0.1 M; pH 9.6) were dropped on the WE $(2 \mu \mathrm{L})$ and incubated for $1 \mathrm{~h}$. The SPEs were then washed twice with $100 \mu$ l of phosphate-buffered saline $(50 \mathrm{mM}$ ) containing $0.1 \%$ tween (PBST; pH 7.4) 
and once with $100 \mu \mathrm{l}$ phosphate-buffered saline (PBS; $50 \mathrm{mM}$; pH 7.4). The WE surface was blocked by dropping $2 \mu \mathrm{L} \mathrm{CB}$ containing $2 \%$ BSA and incubated for 30 minutes. The SPEs were washed again using $100 \mu \mathrm{L}$ PBST (twice) and $100 \mu \mathrm{L}$ PBS (once). Next, $1.6 \mu \mathrm{L}$ of various concentrations of DA-mAb or OA-mAb in reagent buffer (PBST + 1\% BSA; $\mathrm{pH} 7.4$ ) were dropped on the SPE and incubated for 45 minutes. The SPEs were washed again using the same procedure. Next, $1.6 \mu \mathrm{L}$ of various dilutions of rabbit anti-mouse-lgg alkaline phosphatase conjugated polyclonal antibody (pAB-ALP) in reagent buffer was dropped on the SPE and incubated for 30 minutes. After this step a PBS $+1 \%$ tween solution $(\mathrm{pH}$ 7.4) was used to wash $(100 \mu \mathrm{L})$ the SPEs twice followed by one wash $(100 \mu \mathrm{L})$ with PBS. All incubations were performed in a humid chamber at RT. The SPEs were covered with PBS at the end of the incubations and kept in the chamber until measurement. Before measurements the SPEs were carefully tapped dry after which $60 \mu \mathrm{L}$ of diethanolamine buffer (DEA) (1M; pH 9.6) containing 5 mg $\mathrm{mL}^{-1}$ 1-naphthyl phosphate (1-NP) was added. DPV measurements were started after 2 minutes of incubation. Optimisation experiments to determine optimal amounts of DA/OA-mAb, pAb-ALP and DA-BSA/OA-OVA were conducted without toxin addition using a negative control for each condition. The final immunoassays were conducted using addition of toxins spiked in reagent buffer and diluted from $100 \mu \mathrm{g} \mathrm{L}^{-1}$ for $\mathrm{OA}$, and $5000 \mu \mathrm{g} \mathrm{L^{-1 }}$ for DA, down to no toxin addition. Fig. 1 depicts the sensing principle applied.

\section{[Insert Fig. 1. A scheme showing the indirect competitive immunoassay format used for marine} toxin detection.]

\section{Stability study}

Twelve groups of five SPEs were cut out of a sheet of 96 freshly printed SPEs. Six randomly chosen groups of these SPEs were modified with $1.0 \mu \mathrm{L}$ of the $3 \mathrm{mg} \mathrm{mL}^{-1} \mathrm{CB}$ dispersion. The electrochemical performance of one of the groups of CB-SPEs and c-SPEs was immediately characterised (day 0) through CV and EIS experiments. The other groups were vacuum packed and stored in a dark cupboard at RT. The performance of these SPEs was characterised through CV and EIS experiments after 7, 20, 60, 90 and 180 days respectively. Working stability was characterised for both C-SPE and CB-SPEs 
through CV experiments. Briefly, 50 cycles (scan rate $0.05 \mathrm{~V} \mathrm{~s}^{-1}$; step potential $0.01 \mathrm{~V}$ ) were run consecutively for each SPE type $(n=3)$. Anodic peak currents were extracted every fifth CV and used for statistical analyses.

\section{Extraction procedure}

The extraction protocol is adapted from the protocol developed by Chen et al., that was optimised for the simultaneous extraction of hydrophilic and lipophilic marine toxins from algae for LC-MS analyses [32]. Thus, it was decided to look at matrix effects here using post-extraction spiking. Toxin negative homogenized mussel $(1 \mathrm{~g})$ was mixed with $2 \mathrm{~mL}$ of pure methanol and $0.1 \mathrm{M}$ acetic acid $(50 / 50 ; \mathrm{v} / \mathrm{v})$ and shaken vigorously (5 min). PBS ( $27 \mathrm{~mL}$ ) was added and vortexed for 1 minute and the suspension filtered using a syringe filter (Millex-SV; $5 \mu \mathrm{m}$ ). For the immunosensor for OA detection $22 \mu \mathrm{L}$ of the filtrate was added to $178 \mu \mathrm{L}$ reagent buffer. For the immunosensor for DA detection $6 \mu \mathrm{L}$ of the filtrate was added to $194 \mu \mathrm{L}$ reagent buffer. The solutions were then spiked with OA (range 100-0.01 ng mL' ${ }^{1}$ ) or DA (range $5000-0.016 \mathrm{ng} \mathrm{mL}^{-1}$ ). The dilution factors (266X for the OA immunosensor and $1000 \mathrm{X}$ for the DA immunosensor) were chosen to limit the matrix effect and keep enough sensitivity to detect each toxin well below the EU regulated maximum residue levels (MRLs) [5,33].

Interference study

Selectivity of the biosensor for DA detection was tested against the toxins tetrodotoxin (TTX), OA and saxitoxin (STX). For the biosensor detecting OA selectivity was tested against TTX, STX and DA. The concentrations added were $12 \mathrm{ng} \mathrm{mL}^{-1} \mathrm{STX}$ and $0.75 \mathrm{ng} \mathrm{mL}^{-1} \mathrm{TTX}$ for both biosensors. For the biosensor detecting DA; $2.5 \mathrm{ng} \mathrm{mL}^{-1}$ OA was used. For the biosensor detecting OA; $300 \mathrm{ng} \mathrm{mL}^{-1} \mathrm{DA}$ was used. The concentrations chosen represent fourfold (for the OA biosensor) and 16 fold (for the DA biosensor) higher concentrations than the EU regulated or advised (for TTX) action levels in shellfish (taking the dilution factor used for the matrix curves into account) [33] [34]. Additionally, interference of a mixture of $0.75 \mathrm{ng} \mathrm{mL}^{-1} \mathrm{TTX}, 12 \mathrm{ng} \mathrm{mL}^{-1} \mathrm{STX}$ and $2.5 \mathrm{ng} \mathrm{mL}^{-1} \mathrm{OA}$ was tested for the DA biosensor, while interference from a mixture of $0.75 \mathrm{ng} \mathrm{mL}^{-1} \mathrm{TTX}, 12 \mathrm{ng} \mathrm{mL}^{-1} \mathrm{STX}$ and $300 \mathrm{ng} \mathrm{mL}^{-1} \mathrm{DA}$ was tested for the OA biosensor. Interference from L-glutamic acid, L-glutamine, aspartic acid and L-ascorbic acid, 
(usually present in shellfish tissue) was also tested. These compounds were mixed together at $10 \mu \mathrm{g}$ $\mathrm{mL}^{-1}$ per compound in reagent buffer, following the concentrations used in a previous study [28]. The signals obtained with the interfering compounds were compared with the signal obtained at $0 \mathrm{ng} \mathrm{mL}^{-}$ ${ }^{1}, 1 \mathrm{ng} \mathrm{mL}^{-1}$ and $10 \mathrm{ng} \mathrm{mL}^{-1}$ of $\mathrm{OA}$ in reagent buffer for the $\mathrm{OA}$ biosensor and $0 \mathrm{ng} \mathrm{mL}^{-1}, 20 \mathrm{ng} \mathrm{mL}^{-1}$ and $200 \mathrm{ng} \mathrm{mL}^{-1}$ of DA for the DA biosensor. Finally, the cross-reactivity with dinophysis toxins DTX-1, DTX2 and DTX-3 (OA congeners within the diarrheic shellfish toxin group) was calculated for the OA biosensor. The tested range was $2000 \mathrm{ng} \mathrm{mL}^{-1}$ to $0.01 \mathrm{ng} \mathrm{mL}^{-1}$ for DTX1-3 and $100 \mathrm{ng} \mathrm{mL}^{-1}$ to $0.01 \mathrm{ng}$ $\mathrm{mL}^{-1}$ for OA $(\mathrm{n}=3)$. Cross-reactivity was calculated as follows: $\left(\left(\left[I C_{50}\right] \text { for OA }\right) /\left(\left[\mathrm{IC}_{50}\right] \text { for DTX }\right)\right)^{* 100}$.

Statistical analyses and calibration curve fitting ANOVAs, T-tests, Sidak's, and Tukey's multiple comparison adjusted post hoc analyses (with $p=0.05$ as significance cut-off), linear and non-linear regressions, and slope analysis of covariance (ANCOVA) tests were performed in Graphpad v6.0 (San Diego; CA; USA). A four-parameter dose-response curve was used for all non-linear curve fits. LOD, IC 50 and linear range were determined by interpolating $90 \%, 50 \%$ and $20-80 \%$ signal values from the fitted normalised curves respectively. To analyse the EIS data Nyquist plots were fitted in the theoretical equivalent of an adapted Randles Circuit (capacitor replaced by CPE element) using Z-view. The Levenberg-Marquardt algorithm was used to obtain the minimum complex non-linear sum of squares for each fit.

\section{Results and discussion}

\section{Active surface area and working stability}

$\mathrm{CV}$ experiments in $0.1 \mathrm{M} \mathrm{KCl}$ revealed a slight increase in capacitive current $(<0.05 \mu \mathrm{A}$ at the potential range -0.1 to $0.4 \mathrm{~V}$ ) for CB modified SPEs compared to C-SPEs (Fig. 2a). However, the peak anodic current in $\left[\mathrm{Fe}(\mathrm{CN})_{6}\right]^{3-/ 4-}$ was approximately $30 \mu \mathrm{A}$ higher than the peak anodic current for c-SPEs at the same scan rate $\left(0.05 \mathrm{~V} . \mathrm{s}^{-1}\right)$, indicating a substantial increase in the faradic/capacitive current ratio for CB-SPEs compared to c-SPEs. Peak-to-peak separation was clearly reduced compared to c-SPEs at 
any given scan rate and increased less at faster scan rates (Fig. $2 \mathrm{~b})$. The anodic $\left(\mathrm{I}_{\mathrm{A}}\right)$ and cathodic $\left(\mathrm{I}_{\mathrm{C}}\right)$ peak currents increased linearly in function of the square root of the scan rate over a range of 0.01 0.5 V.s $\mathrm{s}^{-1}$ which is characteristic of semi-infinite linear diffusion controlled mass transport (Fig. 2c). An ANCOVA showed that the slopes were clearly different $(p<0.0001)$ with CB-SPE featuring a $\sim 4$ fold more sensitive slope than c-SPE (95\% slope confidence intervals of 255.4 to 264 and -271.6 to -263.9 $\mu \mathrm{A} .\left(V\left(V \mathrm{~s}^{-1}\right)\right)^{-1}$ for $\mathrm{CB}-\mathrm{SPE} \mathrm{I}_{\mathrm{A}}$ and $\mathrm{I}_{\mathrm{C}}$ respectively versus 61.97 to 72.61 and -67.28 to $-57.25 \mu \mathrm{A} .\left(\mathrm{V}\left(\mathrm{V} \mathrm{s} \mathrm{s}^{-1}\right)\right)^{-}$ 1 for C-SPE $I_{A}$ and $I_{C}$ respectively). The slopes obtained were then used to calculate the active surface area of the WEs using the Randles-Sevcik equation for reversible redox processes as described previously [18] (Fig S2a). The active surface area was 0.018 and $0.070 \mathrm{~cm}^{2}$ for c-SPEs and CB-SPEs respectively (a 3.8 fold increase for CB-SPEs with respect to c-SPEs). The working stability of the SPES was also characterised (Fig. 2d). Anodic peak currents increased slightly at consecutive cycles for both electrodes, likely due to similar changes to the WE surface observed with anodic pre-treatment [35]. This increase showed quasi-linear behaviour $\left(R^{2}\right.$ for linear regression lines were 0.63 for c-SPE and 0.89 for CB-SP with a slightly increased slope for CB-SPE compared with c-SPE (ANCOVA; $p<0.05$ ). Yet, internal variance (variance of $\mathrm{I}_{\mathrm{A}}$ over the replicas measured at each CV cycle; Fig. S2b ) was significantly lower (two-tailed T-test $\mathrm{p}<0.0001)$ for CB-SPEs $(2.2 \pm 0.8 \%)$ over all measured CV cycles than for cSPEs $(8.0 \pm 1.4 \%)$. The total \% variance in $\mathrm{I}_{\mathrm{A}}$ (Fig. S2c) was not significantly different for CB-SPE and CSPE (two-tailed T-test $p=0.06$ ) and ranged between $18 \pm 7 \%$ for c-SPE and $15 \pm 5 \%$ for CB-SPE illustrating the importance of keeping CV cycles constant when performing experiments.

[Insert Fig. 2. Cyclic voltammetry characterisations.]

\section{Storage stability}

CV and EIS experiments were conducted using CB/C-SPEs directly after fabrication and after 7, 20, 60, 90 and 180 days of vacuumed storage at RT (Fig. 3). The cyclic voltammograms indicated little change in redox reversibility and electro-catalytic activity over the studied six-month period (Fig. 3a) with CBSPEs always outperforming c-SPEs. A two-way mixed effect ANOVA analyses (Table S1) of the 
extracted anodic peak currents was significant for SPE type and time $(p<0.0001)$. There was no significant interaction effect observed $(p=0.17)$. Post-hoc analyses comparing c-SPE and CB-SPE anodic peak currents at each time point showed that CB-SPEs outperformed c-SPEs at all time-points ( $p<0.0001$ up to $p=0.025$ depending the time-point; table S2). Maximum peak current variance between time-points was $\sim 10 \mu \mathrm{A}$ for both SPE types ( $17 \%$ for CB-SPEs and $\sim 30 \%$ for c-SPEs) (Fig. 3b). Some significant differences in $I_{A}$ between time points within SPE type were observed (Table S3): for CB-SPEs between days 0 and $7(p=0.0086)$ and for $c$-SPEs between days 7 and $180(p=0.01)$ and days 20 and 180 ( $p=0.005)$. No significant differences in $I_{A}$ were observed between days 0 and 180 for any SPE type. Regarding redox reversibility (Fig. 3c) mixed effect ANOVA analyses (Table S4) only showed a significant difference for SPE type $(p<0.0001)$. Post-hoc analyses comparing c-SPE and CB-SPE at each time point showed that CB-SPEs outperformed c-SPEs in redox reversibility at any given time point in the analyses ( $p$ value between 0.0002 and 0.0137 depending the time-point) except at day zero $(p=0.067)$ (Table S5). This non-significant hit at day zero can be attributed to the high variance observed in redox reversibility for c-SPEs. In fact, variance in reversibility was much higher overall for c-SPEs than CB-SPEs (Fig 3c). Stability of the SPEs was characterised by EIS using $\left[\mathrm{Fe}(\mathrm{CN})_{6}\right]^{3-/ 4-}$ with $0.1 \mathrm{M} \mathrm{KCl}$ as the redox probe (Fig 3d-f). Nyquist plots were fitted to a theoretical circuit (Randles circuit with the capacitor replaced by a constant phase element (CPE); Fig. 3d inset panel).

- $\mathrm{Rz} z^{\prime} 0$ describes a combination of the electrolyte, intrinsic material and contact resistance [36].

- Rct describes the electron-transfer resistance and is related to the diameter of the semi-circles observed in the Nyquist plots.

- $\mathrm{Rw}$ is the Warburg resistance and models diffusion resistance. Rw is represented in the Nyquist plots as a line at $45^{\circ}$ increment in the high-frequency range.

- The $\alpha$ values obtained for the CPE describe to which extend the CPE behaves as a capacitor with $\alpha \sim 1$ being an ideal capacitor and decreasing $\alpha$ values between 1 and 0.5 describing increased capacitive dispersion caused by the double layer [37]. 
Fig. 3d and Fig S3 show typical fittings of the data to the model. All fitted curves had $\chi 2$ values $<0.001$. Fig. 3e and Fig. S4 show typical EIS curves obtained for c-SPEs and CB-SPEs at different time points. The most prominent feature observed is the large difference in Rct between the SPE types, with CB-SPEs going almost immediately to diffusion-limited resistance, and c-SPEs having quite large semicircles (Fig. 3d-e). Obtained Rct and $\alpha$ values for all SPEs $(n=5)$ at the tested time points are shown in Fig. 3f. Variance on Rct values was large for c-SPEs. Two-way mixed effect ANOVA analyses of the Rct values (Table S6) was highly significant for SPE type $(p<0.001)$, and slightly significant for interaction $(p<0.05)$. Post-hoc analyses comparing Rct values of the SPEs types at given time points were not always significant. This is probably due to the high variance observed for c-SPE Rct values, however, the average Rct values obtained for CB-SPEs were at least 10-20 fold lower than those obtained for the Rct of c-SPEs at any time point. The gradual decrease in Rct values over time for both electrodes may be due to polymeric linker degradation and better CB surface packing, leading to more effective electron transfer and less capacitive dispersion. The latter assumption is supported by the observed increase in $\alpha$ values over time for CB-SPEs (Fig. 3f). Indeed, two-way mixed effect ANOVA analyses of the $\alpha$ values of the SPE types (Table S7) was highly significant for SPE type, time and interaction $(p<0.0001)$. Post-hoc simple effect analyses within columns showed no significant difference in $\alpha$ values for c-SPEs at various times, but did show significant differences for CB-SPE $\alpha$ values at different times (Table S8) with differences between the groups 0,7 and 20 days (with $\alpha$ values ranging between 0.67 and 0.72 ) and 60, 90 and 180 days (with $\alpha$ values ranging between 0.81 and 0.88$)$ being highly significant $(p<0.0001)$.

[Insert Fig. 3. Six-month stability study. ]

\section{CB-SPE sensitivity for Naphthol detection by DPV}

The sensitivity of CB-SPEs and C-SPEs for the detection of 1-naphthol was determined. The maximum current was obtained from moving baseline corrected DPV peaks and plotted against the 1-naphthol concentration (Fig. 4). The correlation coefficient of the linear range for both the CB-SPE and C-SPE 
was similar with $\mathrm{R}^{2}$ values of 0.995 for the C-SPE and 0.992 for the CB-SPE, both over a range of 0.039$0.625 \mu \mathrm{M}$. An ANCOVA analyses on the slopes of the linear regressions showed the slopes differed significantly from each other $(p<0.0001)$ with a 95\% slope confidence interval of 28.6-32.1 $\mu \mathrm{A} \mathrm{mM}{ }^{-1}$ naphthol for c-SPEs and 70.49 to $81.71 \mu \mathrm{AmM}^{-1}$ naphthol for CB-SPEs. Thus, more variance is observed for CB-SPEs but given the approximately two-fold increase in sensitivity it is considered that CB-SPE is largely superior for monitoring 1-NP substrate conversion by alkaline phosphatase resulting in larger differences in $\mu \mathrm{A}$ over a same concentration range. Moreover, CB-SPE working and storage stability were shown to be superior. Thus, CB-SPEs were chosen for use in immunosensor development.

\section{[Insert Fig. 4. Sensitivity for Napthol.]}

\section{Immunosensors for OA and DA detection}

\section{Assay optimisations}

The immunoreagent amounts were optimised for the detection of DA and OA. To this end the concentrations of toxin-conjugates, DA-mAb, OA-mAb and ALP-pAb were individually varied (Fig. S5 and sup. info.). These studies indicated that $15 \mu \mathrm{g} \mathrm{mL}^{-1}$ toxin-conjugate, $1.0 \mu \mathrm{g} \mathrm{mL}^{-1}$ of mAb and a 1:300 dilution of the pAb-ALP stock concentration were optimum for both immunosensors and were used from hereon. Thus, $6 \mathrm{ng}$ toxin per SPE was needed for the DA biosensor, and $12 \mathrm{ng}$ toxin per SPE for the OA biosensor (see sup. info). This is $125 \mathrm{X}$ less toxin than was used for a similar biosensor for OA detection showing the cost benefit of this approach [15].

\section{Immunosensors}

Calibration curves were constructed for the determination of OA and DA in buffer and shellfish matrix (Fig. 5a-b). DPV curves at varying toxin concentrations showed minimal peak potential difference for both toxins illustrating the stability of the system (Fig. S6). The analytical parameters of the curves shown in Fig. 5 are given in Table 1. The correlation coefficients were excellent for all fitted curves $\left(R^{2}>0.98\right)$ and RSD values remained below $10 \%$ for both biosensors in buffer and in matrix (Table 1$)$. The LOD for DA detection was $1.7 \mathrm{ng} \mathrm{mL}^{-1}$ in buffer. For OA the LOD in buffer was even lower $(0.15 \mathrm{ng}$ 
$\mathrm{mL}^{-1}$ ) showing excellent sensitivity of the CB-SPEs for both immunosensors. Moreover, very little matrix effect was observed in mussel matrix with a LOD of $0.18 \mathrm{ng} \mathrm{mL}^{-1}$ and similar linear range although slightly increased $\mathrm{IC}_{50}$ values for the OA biosensor. Similarly, for the DA biosensor little change in sensitivity (LOD $\left.1.9 \mathrm{ng} \mathrm{mL}^{-1}\right)$ and $\mathrm{IC}_{50}\left(12 \mathrm{ng} \mathrm{ml}^{-1}\right)$ was observed in matrix. However, the linear range was reduced (Table 1). For OA determination in matrix the LOD is $48 \mu \mathrm{g}$ OA eq. kg shellfish-1 and the linear range 93-1037 $\mu \mathrm{g}$ OA eq. Kg shellfish ${ }^{-1}$ taking the applied dilution factor (266X) into account. The maximum regulatory limit (MRL) of OA in shellfish is set at $160 \mu \mathrm{g} \mathrm{OA} \mathrm{eq.} \mathrm{Kg}$ shellfish $^{-1}$ in the EU [33], thus, the LOD of this biosensor is $25 \%$ of the MRL. Importantly, the MRL falls within the linear range of the biosensor. Regarding DA determination in matrix the biosensor showed excellent sensitivity with the LOD (1.9 $\mu \mathrm{g}$ DA eq.kg shellfish $\left.{ }^{-1}\right)$ and IC $\mathrm{C}_{50}\left(12 \mu \mathrm{g}\right.$ DA eq.kg shellfish $\left.{ }^{-1}\right)$ which is $\sim 0.01 \%$ and $\sim 0.06 \%$ of the MRL in the EU (20 mg DA eq. $\mathrm{Kg}_{\text {shellfish }}^{-1}$ ) [5].

\section{Selectivity and biosensor stability study}

\section{Selectivity}

The selectivity of the OA biosensor was determined using non-target and naturally co-occurring marine toxins STX, TTX and DA. Similarly, the selectivity of the DA biosensor was determined using STX, TTX and OA. The non-target toxins were spiked into buffer individually as well as mixed together at 4 and 16 fold their MRL for testing the OA and DA biosensors respectively. Additionally, interference of a mixture of other compounds that naturally occur in shellfish (L-glutamic acid, L-glutamine, aspartic acid and L-ascorbic acid) was also tested (Fig. 5c-d). One-way ANOVAs comparing the signals obtained for the blanks (buffer with no toxin added) with the signals obtained when the toxins or other compounds were mixed into the buffer, were not significant $(p=0.09$ for the OA biosensor; $p=0.17$ for the DA biosensor). However, one-way ANOVAs comparing the obtained signals of the blanks and toxin/interfering compound mixtures with the signal obtained when the target toxins of the respective biosensors were added at relevant concentrations (in and just below the linear ranges of the calibration curves), were highly significant $(p<0.0001)$. All post-hoc comparisons showed a significant difference $(p<0.0001)$ between the signal obtained for the target toxins with the signal obtained for 
the blanks and the non-target toxins or other compounds (Tables S9-10). Moreover, the signals obtained for the different DA concentrations used in the DA biosensor, and the different OA concentrations used in the OA biosensor assay, were significantly different $(p<0.0001)$. Thus, both biosensors showed good selectivity for their respective targets. Finally, cross-reactivity for DTX1-3 was determined for the OA biosensor. The calibration curves for all three toxins showed good fits and allowed DTX1-3 detection with LODs $<10 \mathrm{ng} \mathrm{mL}^{-1}$ (Fig. S7). However, the sensitivity of the biosensor was significantly better for OA, which is why cross-reactivity was low $(0.9 \%$ for DTX-1, $2.1 \%$ for DTX-2 and $9.4 \%$ for DTX-3).

\section{Biosensor stability}

Stability of the biosensors that were functionalised with OA or DA protein conjugates and stored at 4 ${ }^{\circ} \mathrm{C}$ was tested for both biosensors and found acceptable for at least 25 days for the DA biosensor and at least 60 days for the OA sensor (Fig. S8). One-way ANOVAs on the obtained signal at different days (day 1 to day 60 ) with the OA biosensor for 0 and $10 \mathrm{ng} \mathrm{mL}^{-1} \mathrm{OA}$ addition were non-significant $(p=0.214$ and $p=0.301$ respectively). One-way ANOVAs on the obtained signal at different days (day 1 to day 25) with the DA biosensor for 0 and $50 \mathrm{ng} \mathrm{mL}^{-1}$ DA addition were also non-significant $(p=0.092$ and $p=0.384$ respectively). However, a significant reduction in maximum signal ( $0 \mathrm{ng} \mathrm{mL}^{-1} \mathrm{DA}$ addition) at day 60 was observed for the DA biosensor (one-way ANOVA; $\mathrm{p}=0.002$ ) while the signal variation at $50 \mathrm{ng} \mathrm{mL}^{-}$ ${ }^{1}$ DA addition was not significant over that period (one-way ANOVA $p=0.271$ ).

\section{[Insert Fig. 5. Immunosensors and selectivity.]}

\section{[Insert Table 1: Analytical parameters.]}

\section{Conclusion}

CB-SPEs were developed using a high-throughput method involving one automated drop-cast of a stable CB dispersion. Detailed CV and EIS analyses showed that the CB modified electrodes featured 
higher electro-catalytic activity and better redox reversibility than unmodified c-SPEs. Most noteworthy, CB-SPEs showed excellent storage stability for at least six months. EIS analyses indicated that variance in electron transfer resistance after different storage times was much lower for CB-SPES than for c-SPEs. Moreover, internal variance in CV anodic peak currents was significantly reduced for CB-SPEs when compared to c-SPEs. Thus, CB-SPEs seem to be more resistant to long-term storage than bare c-SPEs. The developed immunosensors for the detection of OA and DA had the same optimised immuno-reagent concentrations and functioned very similarly. Moreover, both immunosensors showed sensitive detection of their targets while matrix effects appeared to be minimal using the same sensing principle and platform albeit with two separate biosensors. This is very important as it indicates that piggybacking on the developed devices for the detection of other marine toxins by simply changing recognition element may be relatively straightforward with only minor adaptations, such as changing the dilution factor in sample preparation to match antibody sensitivity, required. However, the observed matrix effect (reduction of the maximum signal in matrix) for the DA biosensor was also observed previously with different electrochemical biosensor using the same antibody, but another detection platform (using immuno-magnetic beads, horseradish-peroxidase conjugated secondary antibody and chronoamperometry) and shellfish species (scallops)[18]. Therefore, it is likely that the observed signal reduction is caused by an undesired interaction between compounds/proteins typically found in shellfish matrix and the DA-mAb causing a slight reduction in binding efficiency leading to a reduction in the maximum signal. Thus, appropriate validation of any biosensor sporting a novel recognition element remains necessary. Overall, the developed biosensors show potential as portable, quantitative tools to measure marine toxins accumulation in shellfish. Such a tool could be used as a screening tool in remote locations and developing countries following detailed validation guidelines such as Decision 2002/657/EC. Such devices may substantially improve shellfish safety standards while lowering food waste (by assisting shellfish-farmers in harvest time and relocation decisions) in a sector that is expected to increase substantially over the next decade. 


\section{Acknowledgements}

This project has received funding from the European Union's Horizon 2020 research and innovation program under the Marie Sklodowska-Curie Grant Agreement No 720325. The BBSRC funding (BB/S004211/1: Safe and sustainable shellfish: Introducing local testing and management solutions) and Dr Dolores Camacho-Muñoz, Professor Christine Edwards and Professor Linda A. Lawton are acknowledged for kindly providing several marine toxins. We thank Professor Fabiana Arduini for kindly providing the $\mathrm{CB}$ used.

\section{References:}

[1] H.C.J. Godfray, J.R. Beddington, I.R. Crute, L. Haddad, D. Lawrence, J.F. Muir, J. Pretty, S. Robinson, S.M. Thomas, C. Toulmin, Food Security: The Challenge of Feeding 9 Billion People, Science (80-. ). 327 (2010) 812-818. https://doi.org/10.1126/science.1185383.

[2] H.C.J. Godfray, I.R. Crute, L. Haddad, D. Lawrence, J.F. Muir, N. Nisbett, J. Pretty, S. Robinson, C. Toulmin, R. Whiteley, The future of the global food system, Philos. Trans. R. Soc. B Biol. Sci. 365 (2010) 2769-2777. https://doi.org/10.1098/rstb.2010.0180.

[3] FAO, The State of World Fisheries and Aquaculture 2018 - Meeting the sustainable development goals., Rome, 2018.

http://www.fao.org/3/i9540en/19540EN.pdf?segid=b273defb-c3b2-4146-9f57b1db87877cfb.

[4] K. Campbell, N. Vilariño, L.M. Botana, C.T. Elliott, A European perspective on progress in moving away from the mouse bioassay for marine-toxin analysis, TrAC - Trends Anal. Chem. 30 (2011) 239-253. https://doi.org/10.1016/j.trac.2010.10.010.

[5] A.S. Tsagkaris, J.L.D. Nelis, G.M.S. Ross, S. Jafari, J. Guercetti, K. Kopper, Y. Zhao, K. Rafferty, J.P. Salvador, D. Migliorelli, G.I.J. Salentijn, K. Campbell, M.P. Marco, C.T. Elliot, M.W.F. Nielen, J. Pulkrabova, J. Hajslova, Critical assessment of recent trends related to screening 
and confirmatory analytical methods for selected food contaminants and allergens, TrAC Trends Anal. Chem. 121 (2019) 115688.

https://doi.org/https://doi.org/10.1016/j.trac.2019.115688.

[6] D. Anderson, HABs in a changing world: a perspective on harmful algal blooms, their impacts, and research and management in a dynamic era of climactic and environmental change, Harmful Algae. 2010 (2012) 3-17.

[7] J.B.M. B.D. Gessner, Seafood and Freshwater Toxins: Pharmacology, Physiology, and Detection, J. Aquat. Food Prod. Technol. (2000) https://doi.org/10.1080/10498850.2015.1024964.

[8] P. Nielsen, B. Krock, P.J. Hansen, B. Vismann, Effects of the DSP-toxic dinoflagellate Dinophysis acuta on clearance and respiration rate of the blue mussel, Mytilus edulis, PLoS One. 15 (2020) e0230176. https://doi.org/10.1371/journal.pone.0230176.

[9] L. Reverté, K. Campbell, M. Rambla-Alegre, C.T. Elliott, J. Diogène, M. Campàs, Immunosensor array platforms based on self-assembled dithiols for the electrochemical detection of tetrodotoxins in puffer fish, Anal. Chim. Acta. 989 (2017) 95-103. https://doi.org/https://doi.org/10.1016/j.aca.2017.07.052.

[10] J.L.D. Nelis, A.S. Tsagkaris, Y. Zhao, J. Lou-Franco, P. Nolan, H. Zhou, C. Cao, K. Rafferty, J. Hajslova, C.T. Elliott, K. Campbell, The End user Sensor Tree: An end-user friendly sensor database, Biosens. Bioelectron. 130 (2019) 245-253. https://doi.org/https://doi.org/10.1016/j.bios.2019.01.055.

[11] S. Cinti, D. Moscone, F. Arduini, Preparation of paper-based devices for reagentless electrochemical (bio)sensor strips, Nat. Protoc. 14 (2019) 2437-2451. https://doi.org/10.1038/s41596-019-0186-y.

[12] F. Ricci, G. Adornetto, G. Palleschi, A review of experimental aspects of electrochemical 
immunosensors, Electrochim. Acta. 84 (2012) 74-83.

https://doi.org/https://doi.org/10.1016/j.electacta.2012.06.033.

[13] L. Micheli, A. Radoi, R. Guarrina, R. Massaud, C. Bala, D. Moscone, G. Palleschi, Disposable immunosensor for the determination of domoic acid in shellfish, Biosens. Bioelectron. 20 (2004) 190-196. https://doi.org/10.1016/j.bios.2004.01.031.

[14] M. Kania, M. Kreuzer, E. Moore, M. Pravda, B. Hock, G. Guilbault, Development of polyclonal antibodies against domoic acid for their use in electrochemical biosensors, Anal. Lett. 36 (2003) 1851-1863. https://doi.org/10.1081/AL-120023618

[15] A. Hayat, L. Barthelmebs, A. Sassolas, J.-L. Marty, An electrochemical immunosensor based on covalent immobilization of okadaic acid onto screen printed carbon electrode via diazotization-coupling reaction, Talanta. 85 (2011) 513-518. https://doi.org/https://doi.org/10.1016/j.talanta.2011.04.034.

[16] F. Scholz, Voltammetric techniques of analysis: the essentials, ChemTexts. 1 (2015) 17. https://doi.org/10.1007/s40828-015-0016-y.

[17] D. Talarico, F. Arduini, A. Constantino, M. Del Carlo, D. Compagnone, D. Moscone, G. Palleschi, Carbon black as successful screen-printed electrode modifier for phenolic compound detection, Electrochem. Commun. 60 (2015) 78-82. https://doi.org/https://doi.org/10.1016/j.elecom.2015.08.010.

[18] J.L.D. Nelis, D. Migliorelli, S. Jafari, S. Generelli, J. Lou-Franco, J.P. Salvador, M.P. Marco, C. Cao, C.T. Elliott, K. Campbell, The benefits of carbon black, gold and magnetic nanomaterials for point-of-harvest electrochemical quantification of domoic acid, Microchim. Acta. 187 (2020). https://doi.org/10.1007/s00604-020-4150-x.

[19] F. Arduini, A. Amine, C. Majorani, F. Di Giorgio, D. De Felicis, F. Cataldo, D. Moscone, G. Palleschi, High performance electrochemical sensor based on modified screen-printed 
electrodes with cost-effective dispersion of nanostructured carbon black, Electrochem. Commun. 12 (2010) 346-350. https://doi.org/https://doi.org/10.1016/j.elecom.2009.12.028.

[20] S. Ramalingam, R. Chand, C.B. Singh, A. Singh, Phosphorene-gold nanocomposite based microfluidic aptasensor for the detection of okadaic acid., Biosens. Bioelectron. 135 (2019) 14-21. https://doi.org/10.1016/j.bios.2019.03.056.

[21] A. Hayat, L. Barthelmebs, J.-L. Marty, Enzyme-linked immunosensor based on super paramagnetic nanobeads for easy and rapid detection of okadaic acid, Anal. Chim. Acta. 690 (2011) 248-252. https://doi.org/https://doi.org/10.1016/j.aca.2011.02.031.

[22] A. Hayat, L. Barthelmebs, A. Sassolas, J.-L. Marty, Development of a novel label-free amperometric immunosensor for the detection of okadaic acid, Anal. Chim. Acta. 724 (2012) 92-97. https://doi.org/https://doi.org/10.1016/j.aca.2012.02.035.

[23] L. Reverté, B. Prieto-Simón, M. Campàs, New advances in electrochemical biosensors for the detection of toxins: Nanomaterials, magnetic beads and microfluidics systems. A review, Anal. Chim. Acta. 908 (2016) 8-21. https://doi.org/https://doi.org/10.1016/j.aca.2015.11.050.

[24] F. Arduini, S. Cinti, V. Mazzaracchio, V. Scognamiglio, A. Amine, D. Moscone, Carbon black as an outstanding and affordable nanomaterial for electrochemical (bio)sensor design, Biosens. Bioelectron. 156 (2020) 112033. https://doi.org/https://doi.org/10.1016/j.bios.2020.112033.

[25] S. Cinti, F. Arduini, M. Carbone, L. Sansone, I. Cacciotti, D. Moscone, G. Palleschi, ScreenPrinted Electrodes Modified with Carbon Nanomaterials: A Comparison among Carbon Black, Carbon Nanotubes and Graphene, Electroanalysis. 27 (2015) 2230-2238. https://doi.org/10.1002/elan.201500168.

[26] F. Arduini, F. Di Nardo, A. Amine, L. Micheli, G. Palleschi, D. Moscone, Carbon Black-Modified Screen-Printed Electrodes as Electroanalytical Tools, Electroanalysis. 24 (2012) 743-751. 
https://doi.org/10.1002/elan.201100561.

[27] V. Mazzaracchio, M.R. Tomei, I. Cacciotti, A. Chiodoni, C. Novara, M. Castellino, G. Scordo, A. Amine, D. Moscone, F. Arduini, Inside the different types of carbon black as nanomodifiers for screen-printed electrodes, Electrochim. Acta. 317 (2019) 673-683. https://doi.org/https://doi.org/10.1016/j.electacta.2019.05.117.

[28] B.J. Yakes, J. Buijs, C.T. Elliott, K. Campbell, Surface plasmon resonance biosensing: Approaches for screening and characterising antibodies for food diagnostics, Talanta. 156157 (2016) 55-63. https://doi.org/10.1016/j.talanta.2016.05.008.

[29] L.D. Stewart, C.T. Elliott, A.D. Walker, R.M. Curran, L. Connolly, Development of a monoclonal antibody binding okadaic acid and dinophysistoxins-1, -2 in proportion to their toxicity equivalence factors, Toxicon. 54 (2009) 491-498.

https://doi.org/https://doi.org/10.1016/j.toxicon.2009.05.015.

[30] N.M. Llamas, L. Stewart, T. Fodey, H.C. Higgins, M.L.R. Velasco, L.M. Botana, C.T. Elliott, Development of a novel immunobiosensor method for the rapid detection of okadaic acid contamination in shellfish extracts, Anal. Bioanal. Chem. 389 (2007) 581-587. https://doi.org/10.1007/s00216-007-1444-3.

[31] A. Sanchis, J.-P. Salvador, K. Campbell, C.T. Elliott, W.L. Shelver, Q.X. Li, M.-P. Marco, Fluorescent microarray for multiplexed quantification of environmental contaminants in seawater samples, Talanta. 184 (2018) 499-506. https://doi.org/https://doi.org/10.1016/j.talanta.2018.03.036.

[32] J. Chen, L. Gao, Z. Li, S. Wang, J. Li, W. Cao, C. Sun, L. Zheng, X. Wang, Simultaneous screening for lipophilic and hydrophilic toxins in marine harmful algae using a serially coupled reversedphase and hydrophilic interaction liquid chromatography separation system with highresolution mass spectrometry, Anal. Chim. Acta. 914 (2016) 117-126. 
https://doi.org/10.1016/j.aca.2016.01.062.

[33] The European Parliament and the Council of the European Union, Regulation (EC) no 853/2004 of the European parliament and of the council of 29 April 2004 laying down specific hygiene rules for food of animal origin foodstuffs, Off. J. Eur. Union. 139 (2004) 151.

[34] L. (Ron) Hoogenboom, H.K. Knutsen, M. Rose, B. Grasl-Kraupp, H. Wallace, B. Viviani, C. Hogstrand, Z. Horvath, M. Binaglia, L. Barregård, J. Alexander, A. Petersen, D. Arcella, N. Arnich, L. Edler, T. Schwerdtle, D. Benford, B. Cottrill, S. Ceccatelli, M. Dinovi, C. Vleminckx, I.P. Oswald, A. Roudot, M. van Manen, H. Steinkellner, B. Brüschweiler, C.S. Nebbia, L. Botana, G. Vollmer, M. Bignami, Risks for public health related to the presence of tetrodotoxin (TTX) and TTX analogues in marine bivalves and gastropods, EFSA J. 15 (2017). https://doi.org/10.2903/j.efsa.2017.4752.

[35] J. Wang, M. Pedrero, H. Sakslund, O. Hammerich, J. Pingarron, Electrochemical Activation of Screen-printed Carbon Strips, Analyst. 121 (1996) 345-350.

[36] E. Umeshbabu, G. Rajeshkhanna, G.R. Rao, Urchin and sheaf-like NiCo2O4 nanostructures: Synthesis and electrochemical energy storage application, Int. J. Hydrogen Energy. 39 (2014) 15627-15638. https://doi.org/10.1016/j.ijhydene.2014.07.168.

[37] J.B. Jorcin, M.E. Orazem, N. Pébère, B. Tribollet, CPE analysis by local electrochemical impedance spectroscopy, Electrochim. Acta. 51 (2006) 1473-1479. https://doi.org/10.1016/j.electacta.2005.02.128. 
FIGURES

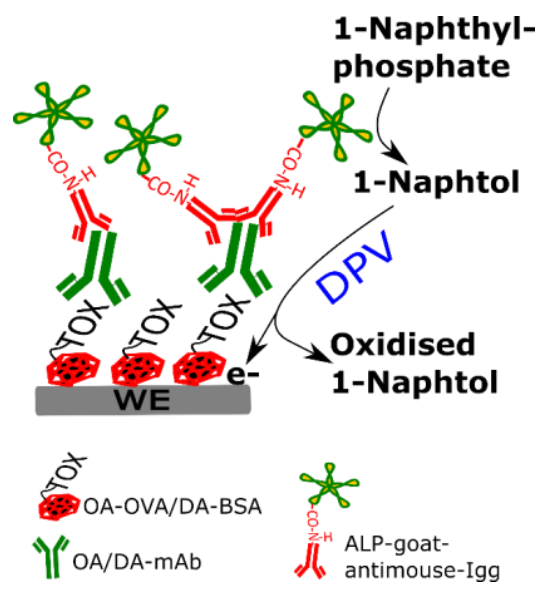

Fig. 1. A scheme showing the indirect competitive immunoassay format used for marine toxin detection. 
a

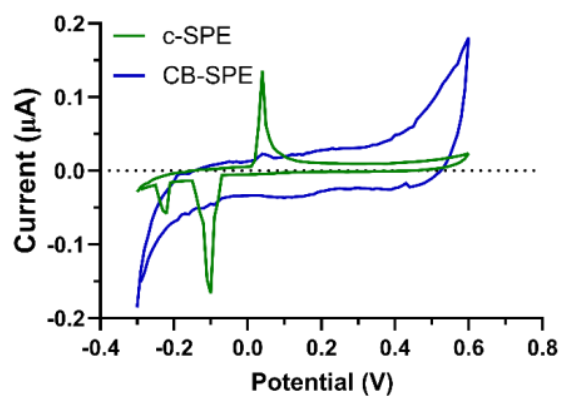

C

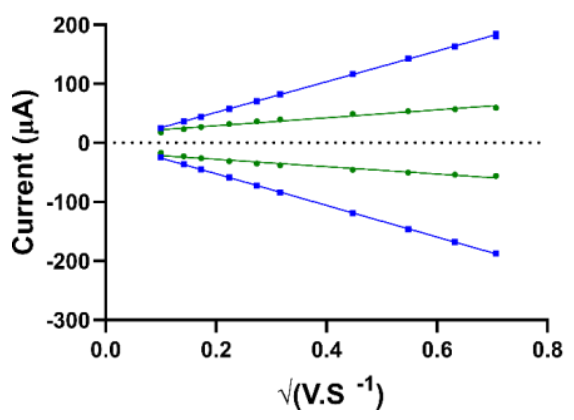

b

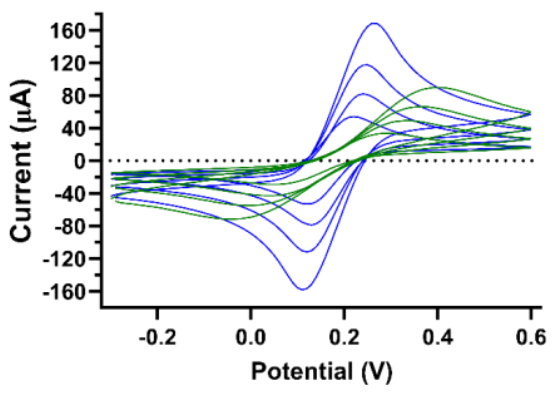

d

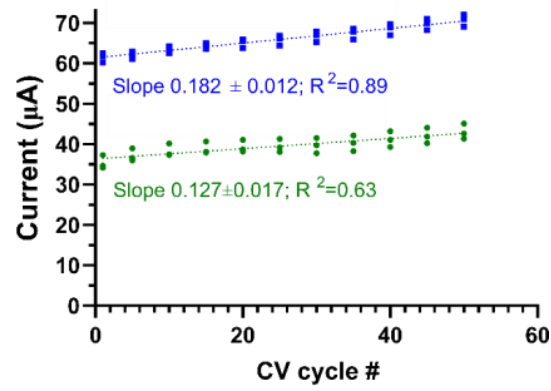

Fig. 2. Cyclic voltammetry characterisations. 

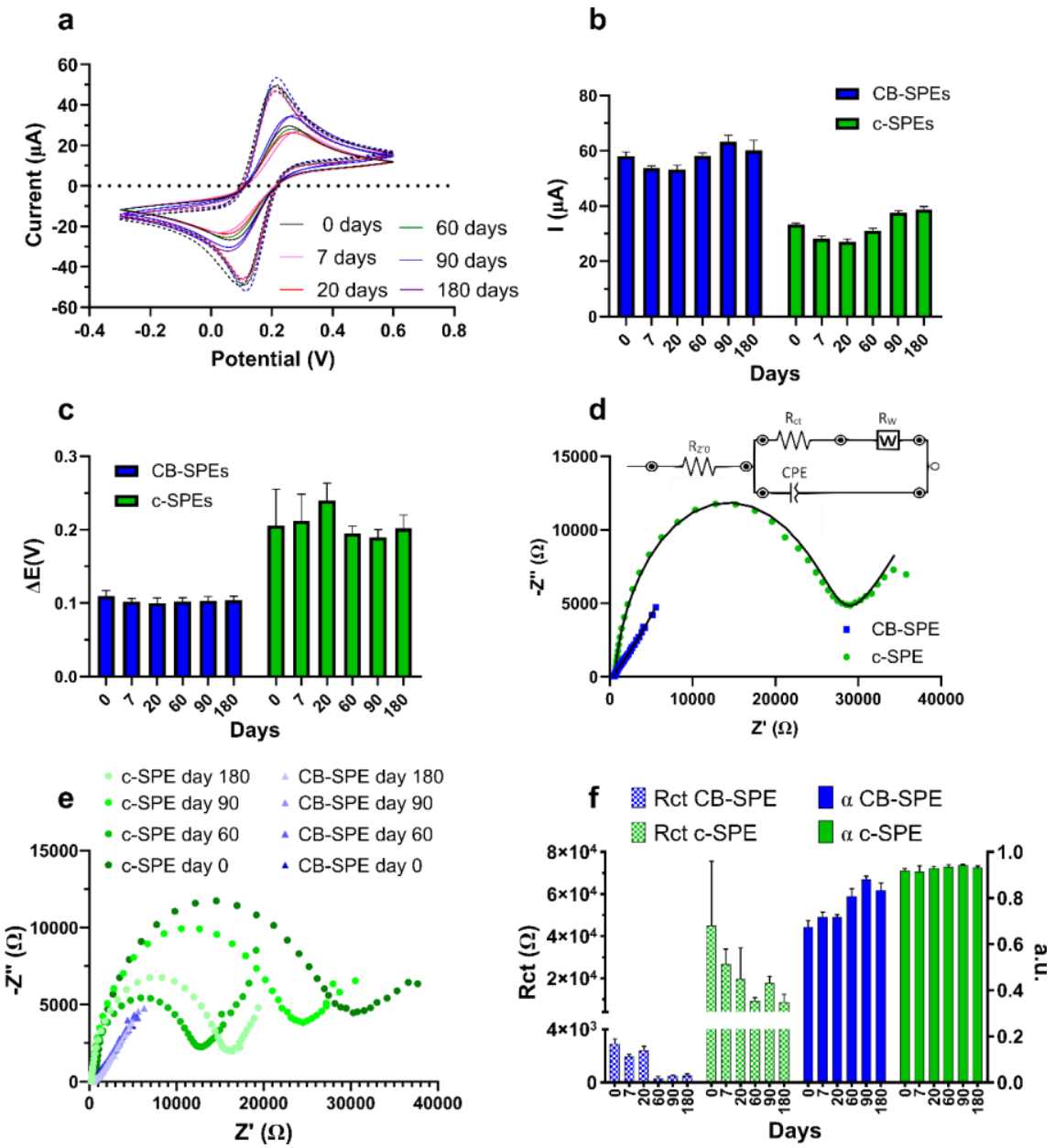

Fig. 3. Six-month stability study. 

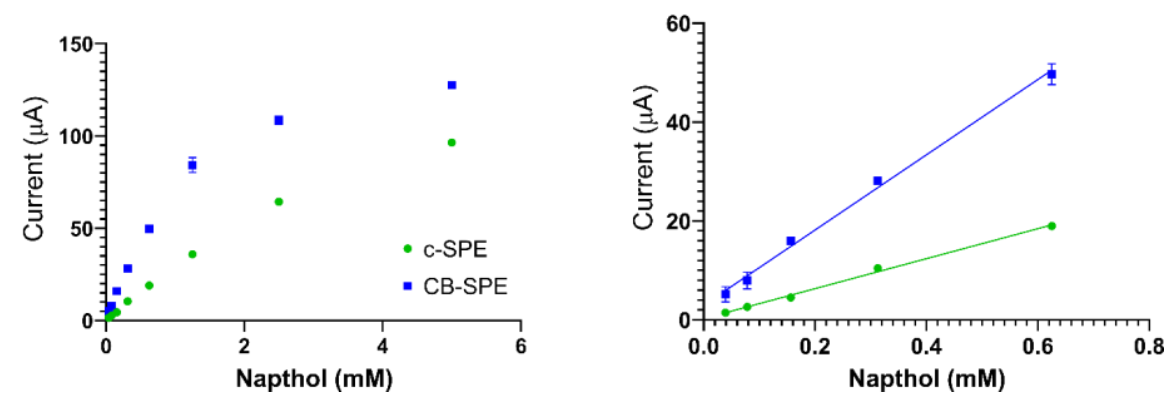

Fig. 4. Sensitivity for Napthol. 

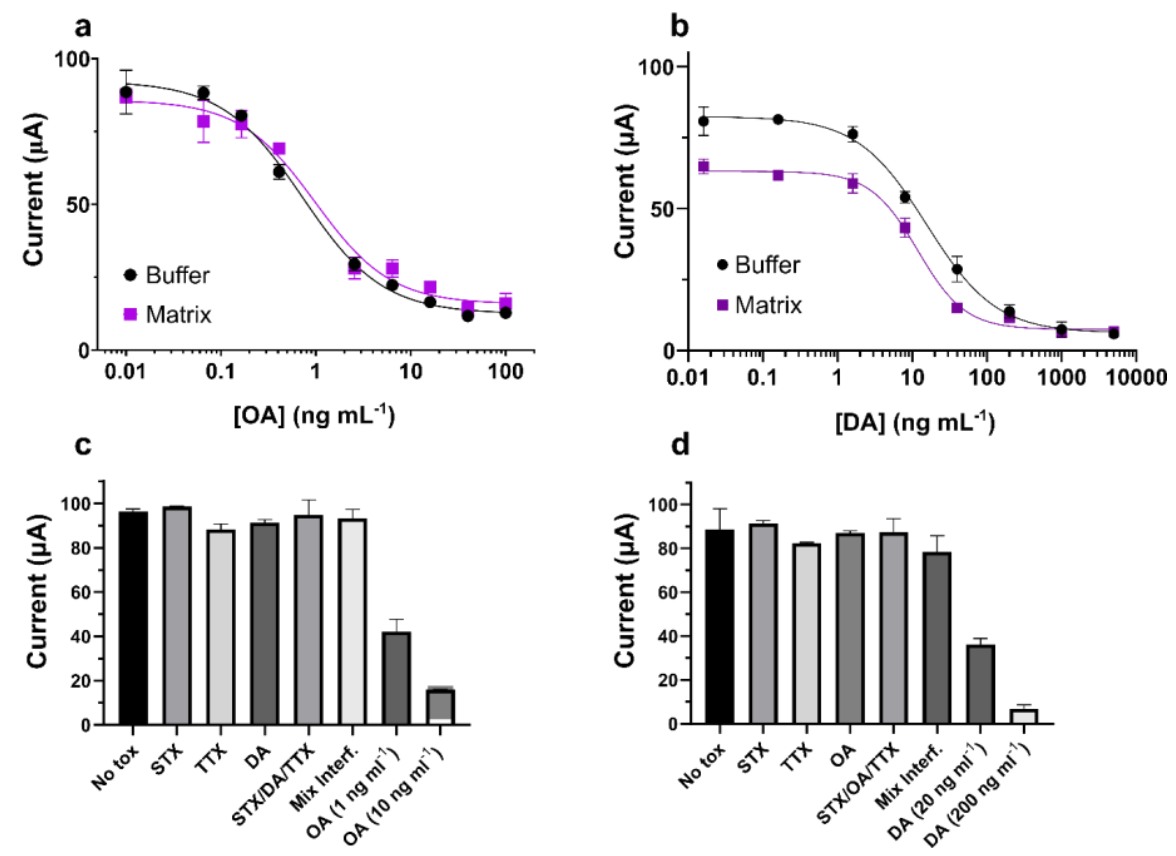

Fig. 5. Immunosensors and selectivity. 


\section{FIGURE CAPTIONS}

Fig. 1. A scheme showing the indirect competitive immunoassay format used for marine toxin detection. mAb-DA or mAb-OA selectively binds to the immobilised toxin-conjugate. After the selective binding between the mAb and pAb-ALP, the ALP catalyses the de-phosphorylation of the non-electroactive substrate (1-Naphthyl-phosphate) into an electroactive product (1-Naphtol) the oxidation of which by DPV will produce the electrochemical signal.

Fig. 2. Cyclic voltammetry characterisations. a) CVs for CB-SPE and C-SPE in $0.1 \mathrm{M} \mathrm{KCl}$ at a scan rate of 0.5 V.S. $\mathrm{S}^{-1}$. b) CVs for c-SPE and CB-SPE in $[\mathrm{Fe}(\mathrm{CN}) 6]^{3-/ 4-}$ with $0.1 \mathrm{M} \mathrm{KCl}$ starting from a scan rate of $0.05 \mathrm{~V} . \mathrm{S}^{-1}$. Consecutive scans were at $0.1,0.2$ and $0.4 \mathrm{~V} . \mathrm{S}^{-1}$. c) Anson plots of CB-SPEs and c-SPEs $(n=3)$ in $\left[\mathrm{Fe}(\mathrm{CN})_{6}\right]^{3-/ 4-}$ with $0.1 \mathrm{M} \mathrm{KCl}$. Error bars are too small to be visualised. Calculated active surface areas of the CB/c-SPEs ( $n=3)$ are shown in Fig. S2a. d) Anodic peak currents extracted from CB-SPEs and c-SPEs $(n=3)$ CVs after one up to 50 cycles every five cycles. Linear regression slopes and $R^{2}$ values are indicated. Fig S2b shows the internal variance between replicas relative to the mean peak current obtained for each individual CV cycle. Fig. S2c indicates the total variance between replicas over all the CV cycles relative to the mean current obtained from the initial CV scan. Green colour was assigned to c-SPEs and blue to the CB-SPEs in all figure panels.

Fig. 3. Six-month stability study. a) Exemplary cyclic voltammograms (CVs) of c-SPEs (full lines) and CB-SPEs (broken lines) in $\left[\mathrm{Fe}(\mathrm{CN})_{6}\right]^{3-/ 4-}$ with $0.1 \mathrm{M} \mathrm{KCl}$ after different storage times (see panel legend). b) Extracted peak currents ( $n=5)$ from CVs of c-SPEs and CB-SPEs at various time points. c) Extracted $\triangle E$ values $(n=5)$ from CVs of $c$-SPEs and CB-SPEs at various time points. d) Nyquist plot of the EIS analysis of C-SPE and CB-SPEs recorded directly after fabrication in $[\mathrm{Fe}(\mathrm{CN}) 6]^{3-/ 4-}$ with $0.1 \mathrm{M} \mathrm{KCl}$. An adapted Randles circuit (top inset figure) was fitted (black lines) to the data to extract CPE, $\alpha$ and $R_{c t}$ values. A zoomed in image of this CB-SPE measurements and plot fit is shown in Fig. S3. e) Exemplary Nyquist plot of the EIS analysis of c-SPEs and CB-SPEs in $[\mathrm{Fe}(\mathrm{CN}) 6]^{3-/ 4-}$ with $0.1 \mathrm{M} \mathrm{KCl}$ after different storage times (see panel legend). A zoomed image of the Nyquist plot for CB-SPEs is shown in Fig. S4. f) $R_{c t}$ and CPE values extracted from EIS measurements $(n=5)$ of c-SPEs and CB-SPEs after different storage times. Rct values are plotted against the left $\mathrm{Y}$-axes, $\alpha$ values are plotted against the right $\mathrm{Y}$ axes.

Fig. 4. Sensitivity for Napthol. DPV measurements $(n=3)$ were performed on both SPEs by adding 50 $\mu \mathrm{L}$ of DEA containing $10 \mu \mathrm{M}$ to $5 \mathrm{mM}$ 1-naphthol. Peak currents were obtained from baseline corrected DPV peaks.

Fig. 5. Immunosensors and selectivity. a-b) Calibration curves for OA (a) and DA (b) determination in buffer (black points) and in mussel extract (purple squares) at various toxin concentrations $(n=3)$. The analytical parameters of the calibration curves are given in Table 1. c-d) Peak DPV currents for the OA biosensor $(c)$ and DA biosensor $(d)$ interference studies. No tox is the blank sample (reagent buffer). STX is spiked in the reagent buffer at $12 \mathrm{ng} \mathrm{mL}^{-1}$ and TTX at $0.75 \mathrm{ng} \mathrm{mL}^{-1}$ for both curves. DA is spiked at $300 \mathrm{ng} \mathrm{mL}^{-1}$ in (c) and 20 and $200 \mathrm{ng} \mathrm{mL}^{-1}$ in (d). OA is spiked at 1 and $10 \mathrm{ng} \mathrm{mL}^{-1}$ in (c) and $2.5 \mathrm{ng} \mathrm{mL}^{-1}$ in (d). STX/DA/TTX and STX/OA/TTX are mixture of the 3 toxins at the same concentrations as used for the individual toxins for the OA and DA biosensors respectively. Mix Interf. is a mixture of L-glutamic acid, L-glutamine, aspartic acid and L-ascorbic acid at $10 \mu \mathrm{g} \mathrm{m}^{-1} \mathrm{per}$ compound. 


\section{TABLE}

Table 1: Analytical parameters. The $L O D, I C_{50}$ and linear-range were obtained by interpolating $90 \%$, $50 \%$ and $20-80 \%$ signal values respectively from a four-parameter dose-response curve fitted to normalised data. Assay type, $\mathrm{R}^{2}$ value, RSD, target, SPE modification as well as matrix used are indicated.

\begin{tabular}{|c|c|c|c|c|c|c|}
\hline Assay & Matrix & $\operatorname{LOD}\left(\mathrm{ng} \mathrm{mL} \mathrm{L}^{-1}\right.$ ) & $\begin{array}{c}\mathrm{IC}_{50} \\
\text { (ng.mL } \mathrm{mL}^{-1} \text { ) }\end{array}$ & $\begin{array}{l}\text { Lin. Range } \\
\text { (ng. mL }{ }^{-1} \text { ) }\end{array}$ & $\mathbf{R}^{2}$ & RSD (\%) \\
\hline DA CB-SPE & Buffer & 1.7 & 16 & $4-72$ & 0.99 & $8.7 \pm 9.0 \%$ \\
\hline DA CB-SPE & Mussel & 1.9 & 12 & $4-34$ & 0.99 & $5.6 \pm 4.1 \%$ \\
\hline OA CB-SPE & Buffer & 0.15 & 0.9 & 0.27 to 3.3 & 0.99 & $6.1 \pm 4.1 \%$ \\
\hline OA CB-SPE & Mussel & 0.18 & 1.13 & $0.35-3.9$ & 0.98 & $7.2 \pm 5.2 \%$ \\
\hline
\end{tabular}

